Original Research Paper

\title{
Inhibition of Interleukin-6 Expression by Curcumin in Rat Vascular Smooth Muscle Explants In Vitro
}

\author{
${ }^{1}$ Yanti, ${ }^{1}$ Stephanie, ${ }^{1}$ Yuliani, ${ }^{1}$ F.G. Winarno and ${ }^{2}$ Maggy T. Suhartono \\ ${ }^{1}$ Faculty of Biotechnology, Atma Jaya Catholic University, Jalan Jenderal Sudirman 51, Jakarta 12930, Indonesia \\ ${ }^{2}$ Department of Food Science and Technology, Bogor Agricultural University, Bogor 16680, West Java, Indonesia
}

\author{
Article history \\ Received: 18-09-2014 \\ Revised: 21-11-2014 \\ Accepted: 03-12-2014 \\ Corresponding Author: \\ Yanti, \\ Faculty of Biotechnology, \\ Atma Jaya Catholic University, \\ Jalan Jenderal Sudirman 51, \\ Jakarta 12930, Indonesia \\ Tel: +62 215703306 ext 722; \\ Fax: +62 215719060 \\ Email: yanti@atmajaya.ac.id
}

\begin{abstract}
In atherosclerotic plaques, infectious agents from microbes may release Lipopolysaccharide (LPS) and heat shock proteins that can stimulate the production of mediators, i.e., pro-inflammatory cytokines, by vascular endothelial cells and Smooth Muscle Cells (SMCs). The elevated level of Interleukin-6 (IL-6) is strongly associated with the development of atherosclerosis. Here, we investigated whether curcumin isolated from the rhizome of Curcuma longa affected the expression of IL-6 at protein and gene levels in rat smooth muscle cells treated with LPS in vitro by conducting ELISA and Reverse Transcriptase-Polymerase Chain Reaction (RT-PCR) assays. LPS at $2 \mu \mathrm{g} \mathrm{mL} \mathrm{m}^{-1}$ activated the expression of IL-6 protein and mRNA in SMCs. Curcumin $(1-15 \mu \mathrm{M})$ caused the decreased levels of IL-6 protein and mRNA in the dose-dependent manner in LPSinduced SMCs, indicating its potential antiatherosclerotic effect for cardiovascular risk management. In addition, curcumin also partially blocked the activation of LPS-induced phosphorylation of MAP kinases, i.e., ERK1/2, p38 and JNK, in SMCs, suggesting it may inhibit IL-6 expression via attenuating MAP kinase signaling pathways in LPS-induced SMCs. These data may in part explain the molecular action of antiatherosclerotic effects of curcumin.
\end{abstract}

Keywords: Curcumin, Curcuma Xanthorrhiza Roxb., Interleukin-6, MAP Kinase, Rat Smooth Muscle Cells

\section{Introduction}

The use of medicinal plants for management of diseases is recognized to be associated with folk medicine from different parts of the world. Nowadays, natural products derived from plants have been well explored to be used in pharmaceutical purposes either as pure compounds or as extracts. For example, the rhizomes of Curcuma longa L. or turmeric, locally known as kunyit in Indonesia and belong to the Zingiberaceae family, have been widely studied due to its potential use for culinary and medicinal functions against biliary disorders, anorexia, coryza, cough, diabetic wounds, hepatic disorder, rheumatism and sinusitis (Araujo and Leon, 2001). C. longa rhizomes are rich in curcumin (diferuloylmethane), demethoxycurcumin, bisdemethoxycurcumin and essential oils (tumerone, atlantone and zingiberone). It has been noted that curcumin as the major constituent in C. longa exerted numerous pharmacological activities including anti-ulcer, anticancer, anti-inflammatory, anti-diabetic, anti-obesity and antimicrobial effects (Tuorkey and Karolin, 2009; Aggarwal 2010; Zhou et al., 2011). Due to its use as anti-inflammatory candidate, unfortunately, the efficacy study on inflammation-related atherosclerosis through modulating cytokine expression is rarely conducted till present.

Bacterial endotoxin or lipopolysaccharide promotes the activation of several kinases that are known to participate in inflammatory pathways including extracellular signal-related kinase 1/2 (ERK1/2) and p38 in vascular cells (Weinstein et al., 1992). The activation of these Mitogen Activated-Protein (MAP) kinase pathways is a critical mechanism by which LPS causes chronic inflammation and contributes to CVD. The three major groups of MAPKs that regulate gene expression are ERK1/2, p38 and c-Jun N-terminal Kinase (JNK). Mitogens and growth factors primarily activate ERK1/2. In contrast, JNK and p38 are activated by proinflammatory cytokines such as Interleukin (IL)-1 $1 \beta$ and Tumor Necrosis Factor (TNF)- $\alpha$ and cell stress-inducing factors such as heat shock, 
ultraviolet radiation and oxygen radicals (Han et al., 1993; Lee et al., 1994). In this study, we investigate whether curcumin isolated from the rhizome of $C$. longa might be effective for attenuating IL-6 expression in LPS-induced vascular smooth muscle cells via modulating MAP kinase signaling mechanism.

\section{Materials and Methods}

\section{Plant Materials}

Dried rhizomes of Curcuma longa Roxb. were collected from traditional markets in Jakarta and identified by Herbarium Bogoriense, Bogor Botanical Garden, Bogor. A voucher specimen (L003) is deposited in Faculty of Biotechnology, Atma Jaya Catholic University, Jakarta.

\section{Isolation of Curcumin}

Curcumin was isolated from the methanol extract of C. longa. Briefly, the dried rhizomes (100 g) were grounded and extracted with $75 \% \mathrm{MeOH}(\mathrm{v} / \mathrm{v}, 400 \mathrm{~mL})$. The concentrated methanol extract was fractioned successively with ethyl acetate, n-butanol and water. Curcumin was isolated from the ethyl acetate fraction using silica gel column chromatography (Merck; 70-230 meshes, $5 \times 43 \mathrm{~cm}$, n-hexane-ethyl acetate $510: 1, \mathrm{v} / \mathrm{v})$. Curcumin was identified by direct comparison of the ${ }^{1} \mathrm{H}-$ Nuclear Magnetic Resonance (NMR), ${ }^{13} \mathrm{C}-\mathrm{NMR}$ and Electron Ionization (EI)-mass spectral results with previously published data (Roughley and Whiting, 1973).

\section{Cell Culture and Cell Viability}

Rat mesenteric artery smooth muscle cells were isolated and cultured as previously described by (Gunther et al., 1982) with slight modification. Briefly, male C-D strain Sprague-Dawley rats (225-250 g) were killed by cervical dislocation and the superior mesenteric arterial arcade was aseptically excised. Fat, adventitia and veins were removed by blunt dissection and the remaining arterial tree was incubated with elastase, collagenase, soybean trypsin inhibitor and bovine albumin at $37^{\circ} \mathrm{C}$ in a gyratory shaker bath. After repeated tituration and sieving, the resulting cell suspension was washed by centrifugation and plated in Dulbecco's Modified Eagle's Medium (DMEM) with $10 \%$ Fetal Serum Albumin (FBS), $2 \mathrm{mM}$ L-glutamine, $25 \mathrm{mM}$ HEPES buffer, $100 \mathrm{U} / \mathrm{mL}$ penicillin and $0.1 \mathrm{mg}$ $\mathrm{mL}^{-1}$ streptomycin. Similar methods were used for production of rat aortic smooth muscle cultures by enzymatic dissociation.

The cells were normally plated at a density of $\sim 5 \times 10^{4} \mathrm{CFU} / \mathrm{mL}$ in plastic culture dishes or on glass coverslips that had been precoated with human fibronectin. Fibronectin-coated coverslips were used for increased cell adhesion; this treatment had no apparent effect on growth or staining patterns. Cultures were incubated at $37^{\circ} \mathrm{C}$ in a humidified atmosphere of $5 \% \mathrm{CO}_{2}$ with thrice weekly media changes. The protocol has been approved by Animal Care and Use Committee of Primate Research Center, Bogor Agricultural University (Indonesia).

\section{Sample Preparation}

Curcumin was dissolved in $100 \%$ dimethyl sulfoxide (DMSO) and diluted to the final concentrations of 1-50 $\mu \mathrm{M}$ using 10\% DMSO. Resveratrol as reference standard was also dissolved in $100 \%$ DMSO and diluted to the final concentration of $15 \mu \mathrm{M}$ in $10 \%$ DMSO.

\section{Enzyme-Linked Immunosorbent Assay (ELISA)}

IL-6 concentration in media were synthesized during inflammation was quantified by ELISA according to ELISA manufacturer's protocol (R\&D Systems). Briefly, a 96-well plate that was pre-coated with a monoclonal antibody specific for rat IL-6 was incubated with $50 \mu \mathrm{L}$ sample which has been diluted by calibrator diluents and standard or control to each well, following incubation for $2 \mathrm{~h}$ at room temperature. To wash specific unattached sample with antibody, plate was washed by wash buffer five times using automated plate washer. After the last wash, the plate was reversed in the paper towels to dry the wells for optimal results.

A $100 \mu \mathrm{L}$ Horseradish Peroxidase (HRP) conjugated secondary antibody was added to wells and were incubated for another $2 \mathrm{~h}$ at room temperature and then washed five times. Plate was incubated $30 \mathrm{~min}$ with 100 $\mu \mathrm{L}$ substrate tetramethylbenzidine but protected from light exposure. The color will turn from blue to yellow was occurred after acidification with $100 \mu \mathrm{L} \mathrm{HCl}$. During the procedures, the plate should be sealed with adhesive strip. OD was measured at wavelength of 450 $\mathrm{nm}$ by Microplate Reader with reference wavelength 595 $\mathrm{nm}$ using ELISA reader.

\section{Reverse Transcription-Polymerase Chain Reaction (RT-PCR)}

Total RNA from LPS-induced artery SMCs was extracted using Trizol reagent according to the manufacturer's protocol and quantified spectrophotometrically at $260 / 280 \mathrm{~nm}$. The cDNA was synthesized by using $1 \mu \mathrm{g}$ total RNA, oligo(dT) primers and SuperScript III First-Strand (Invitrogen) in a $10 \mu \mathrm{L}$ reaction. Reverse transcription was started at $50^{\circ} \mathrm{C}$ for 50 min and terminated at $85^{\circ} \mathrm{C}$ for $5 \mathrm{~min}$. The cDNA products were diluted with sterile water up to $100 \mu \mathrm{L}$ and PCR was conducted using $5 \mu \mathrm{L}$ cDNA in a $25 \mu \mathrm{L}$ reaction system with $0.5 \mathrm{U}$ Takara LA Tag (Takara Bio).

The rat oligonucleotide primers for IL- 6 and betaactin were designed according to a PCR primer selection program at the website of the Virtual Genomic Center from the GenBank database. IL-6 primers were set up as 5' GGGTCGGTTCTGACCTTTTG3' for forward and 5' CTCTGTCCCTAATGCCCAGT3' for reverse. 
Meanwhile, beta-actin primers were 5, AGCCATGTACGTAGCCATCC3' for forward and 5' CTCTCAGCTGTGGTGGTGAA 3' for reverse. PCR consisted of 30 amplification cycles and each cycle was carried out for $30 \mathrm{~s}$ at $94^{\circ} \mathrm{C}, 1 \mathrm{~min}$ at $55^{\circ} \mathrm{C}$ and 1 min at $72^{\circ} \mathrm{C}$ in a thermal cycler (Gene Amp PCR System 2700). The rat beta-actin housekeeping gene was used as an internal control to standardize the relative expression levels for MMP-9. PCR products were separated electrophoretically in a $2 \%$ agarose DNA gel and stained with ethidium bromide. The stained gel was visualized by Gel-Doc Quantity One software (Bio-Rad). The relative expression level of IL-6 mRNA from the untreated and treated cells were calculated and expressed as ratios.

\section{Western Blot}

To determine the expression of phosphorylated and total MAPKs, cellular lysates from the negative control, positive control and treatment group (curcumin) were prepared and assayed by Western blot analysis. Proteins $(25 \mu \mathrm{g})$ were resolved by $10 \%$ SDS-PAGE and transferred to nitrocellulose transfer membranes. The membranes were blocked with 5\% skim milk for $1 \mathrm{~h}$ at room temperature and then probed with the primary antimouse monoclonal antibodies against p-ERK1/2, p-p38, p-JNK at a 1:1000 dilution overnight at $4{ }^{\circ} \mathrm{C}$. After three washes, the blots were subsequently incubated with the secondary antibody peroxidase-conjugated anti-mouse $\mathrm{IgG}$ at a 1:4000 dilution for $2 \mathrm{~h}$ at room temperature. The blots were stained with SuperSignal West Femto Maximum sensitivity substrate (Thermo Scientific) and visualized using a LAS 3000 Bio Imaging Analysis System (Lab Science).

\section{Statistical Analysis}

Triplicate experiments were performed throughout this study. All data are presented as the mean \pm Standard Deviation (SD). The significant difference between control and treated groups were statistically analyzed by the paired Student's $t$-test $(\mathrm{p}<0.05)$.

\section{Results and Discussion}

\section{Effect of Curcumin on the Viability and Morphology of Vascular Smooth Muscle Cells in Vitro}

Curcumin (Fig. 1a), a hydrophobic phenol compound with molecular weight of 368 , was successfully isolated from $C$. longa rhizomes. Curcumin was preliminary tested for its cytotoxicity against vascular smooth muscle cell viability and morphology. Our MTT results revealed that curcumin up to $15 \mu \mathrm{M}$ did not affect both cell viability and morphology (Figs. 1b and 1c), suggesting the compound is not toxic within tolerance concentrations and used for further experiment.
Effect of Curcumin on the Expression of Interleukin-6 Protein and $m R N A$ in Lipopolysaccharide-Induced Vascular Smooth Muscle Cells in Vitro

As shown in Fig. 2, the presence of LPS significantly induced the expression of IL- 6 protein level in the cell system. LPS plays a major role in stimulating the inflammation response including atherosclerosis and possesses various biological activities of pyrogenicity, mitogenicity, activated macrophages and adjuvant (Stimpson et al., 1987). Exogenous LPS causes the changes in metabolism and stimulates the production of pro-inflammatory cytokines (Interleukin (IL)-1, IL-6, Tumor Necrosis Factor (TNF)- $\alpha$ and Interferon (IFN)- $\gamma$ ) and inflammatory enzymes (MMP-9, Cyclooxygenase (COX)-2 and inducible Nitric Oxide Synthetase (iNOS) in various cells (Zhang et al., 2000). Our previous study showed that LPS stimulated the expression of MMP-2 and -9 in vascular epithelial cells in vitro (Yanti, 2010).

Further sample treatment using curcumin at various concentrations $(5,10$ and $15 \mu \mathrm{M})$ was conducted. Our results demonstrated that curcumin dose-dependently caused the reduced level of IL- 6 protein production in LPS-induced vascular smooth muscle cells in vitro (Fig. $2)$. Interestingly, it efficacy on decreasing IL-6 protein level was similar with the standard resveratrol. In line with this study, epigallocathecin gallate, areca nut, saikosaponin, peptidoglycan, curcuminoid and ginkgo biloba extract were also reported for their potential IL-6 inhibitory effects in various vascular and inflammatory cells (Schiborr et al., 2010; Wu et al., 2010; Lin et al., 2011; Lin et al., 2012).

At the gene level, curcumin also dose-dependently blocked the mRNA expression of IL-6 in the LPSinduced vascular smooth muscle cells in vitro (Fig. 3). These results clearly demonstrated that curcumin significantly affected the expression of IL-6 at protein and gene levels. Therefore, we further determined whether curcumin interfered signaling mechanisms mediated IL-6 gene expression in LPS-induced vascular smooth muscle cells in vitro.

Effect of Curcumin on MAP Kinase Signaling Involved in Interleukin-6 mRNA Expression in Lipopolysaccharide-Induced Vascular Smooth Muscle Cells in Vitro

It has been known that LPS stimulate cytokine production including IL- 6 through the activation of MAP kinases, nuclear factor- $\kappa \beta$, inhibitor $\kappa \beta$ kinase and Activator Protein (AP)-1 in various cell culture and animal models (Cohen et al., 2009; Rafiee et al., 2009; Wang et al., 2009; $\mathrm{Li}$ et al., 2010). However, the upstream signaling molecules that responsible to regulate these signalings remain unclear in vascular smooth muscle cells. 


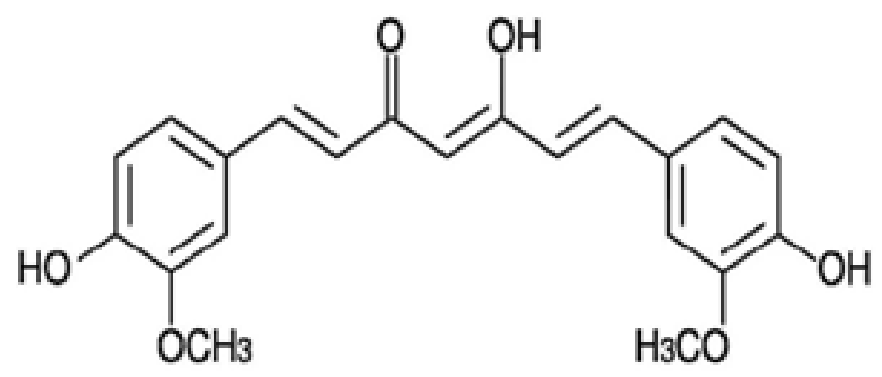

(a)

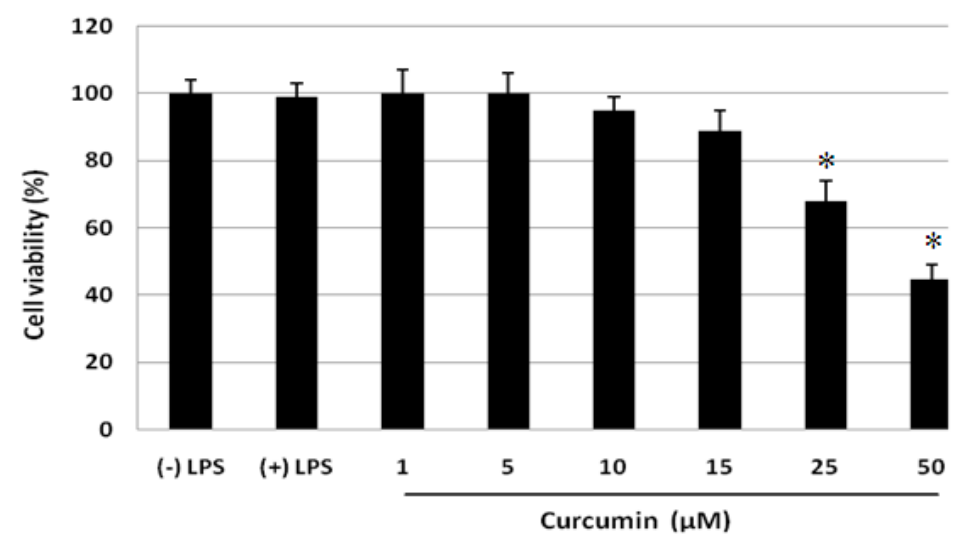

(b)

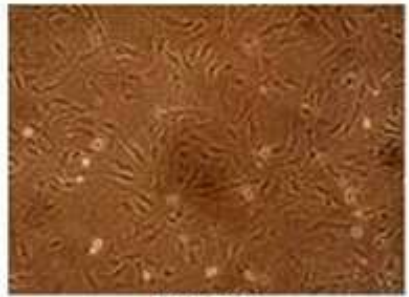

$(-)$ LPS

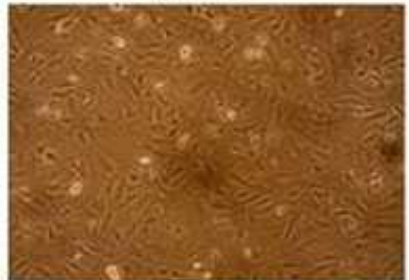

Curcumin $5 \mu \mathrm{M}$

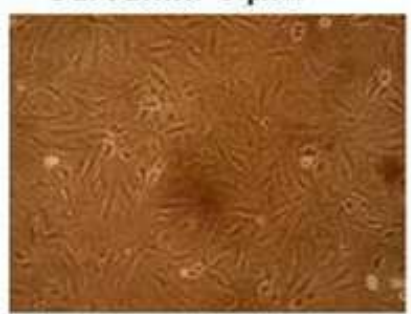

Curcumin $25 \mu \mathrm{M}$

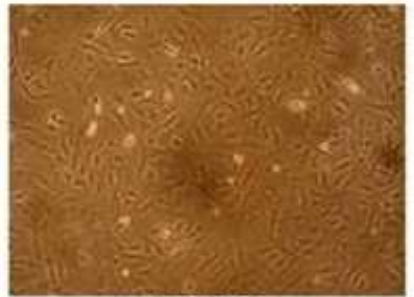

(+) LPS

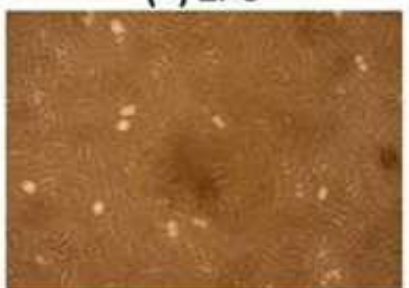

Curcumin $10 \mu \mathrm{M}$

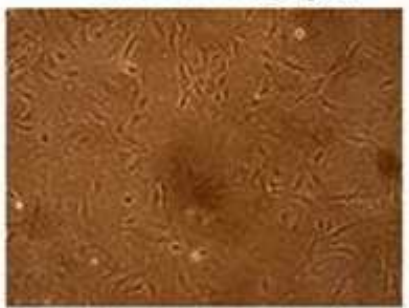

Curcumin $50 \mu \mathrm{M}$

(c)

Fig. 1. Effect of curcumin (a) on vascular smooth muscle cell viability (b) and morphology (c) in vitro, ${ }^{*} P<0.05$ vs LPS-treated cells 


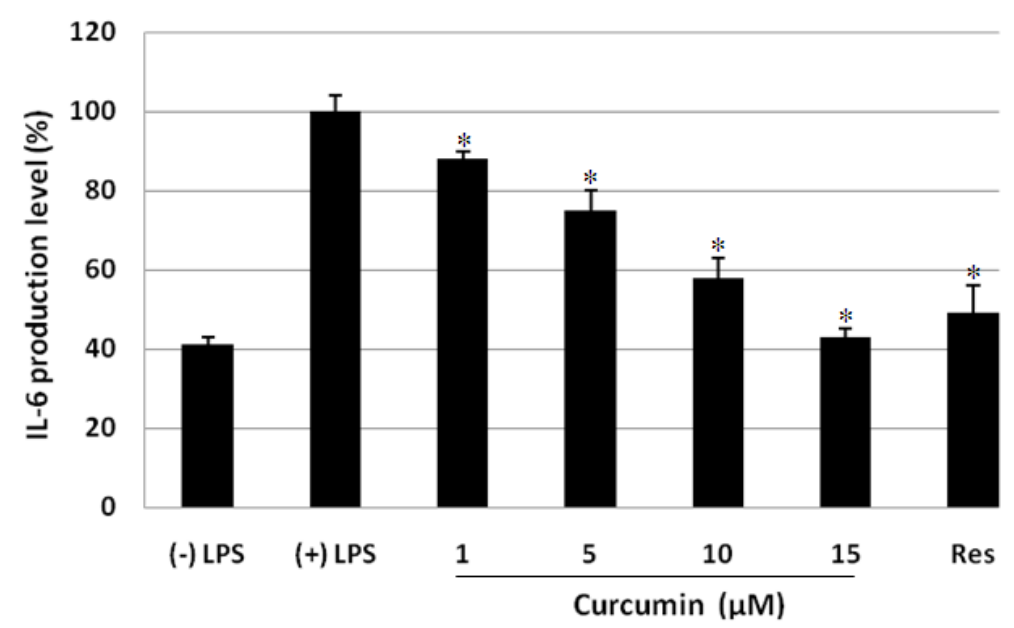

Fig. 2. Effect of curcumin on the level production of IL-6 protein in smooth muscle cells in vitro by ELISA assay, Res (15 $\mu$ M) indicated resveratrol standard, $* P<0.05$ vs LPS-treated cells

$\operatorname{LPS}\left(2 \mu \mathrm{g} \mathrm{mL} L^{-1}\right)$

Curcumin $(\mu \mathrm{M})$

Resveratrol $(\mu \mathrm{M})$

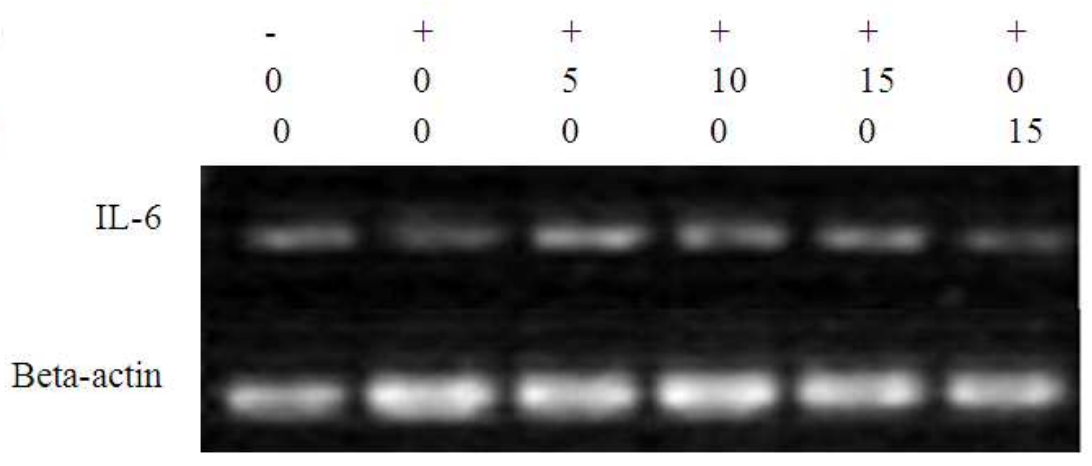

Fig. 3. Effect of curcumin on the expression of IL-6 mRNA in smooth muscle cells in vitro by RT-PCR assay. Res (15 $\mu \mathrm{M})$ indicated resveratrol (standard)

\section{$\operatorname{LPS}\left(2 \mu \mathrm{g} \mathrm{mL} \mathrm{m}^{-1}\right)$}

Curcumin $(\mu \mathrm{M})$

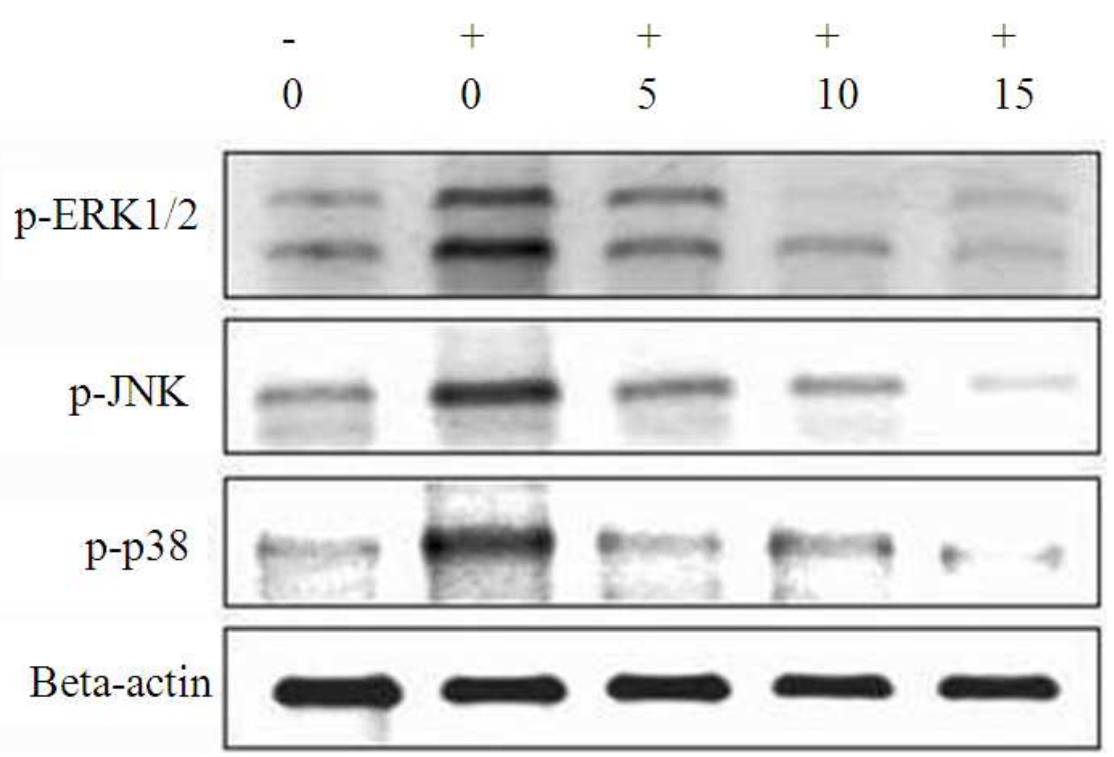

Fig. 4. Effect of curcumin on phosphorylation of ERK1/2, JNK and p38 in LPS-induced vascular smooth muscle cells in vitro by Western blot assay 
In this study, LPS induced the expression of phosphorylated JNK, p38 and ERK1/2 in vascular smooth muscle cells (Fig. 4). Curcumin at concentrations of 5,10 and $15 \mu \mathrm{M}$ were found to equally inhibit the activating phosphorylation of JNK, p38 and ERK1/2 in the cell system. Our findings provide evidence for the role of curcumin on LPSinduced IL-6 gene expression by modulating MAP kinase signaling pathways in vascular smooth muscle cells. Together with this study, inhibition of MAPK phosphorylation by naturally-occurring agents presents an attractive strategy to block the excess production of IL-6 for prevention and treatment of CVD (Chang et al., 2009; Schiborr et al., 2010; Wu et al., 2010; Lin et al., 2011; Lin et al., 2012).

\section{Conclusion}

The inhibition of phosphorylated JNK, p38 and ERK1/2 signalings may be one of the molecular mechanisms by which curcumin inhibits regulation of IL-6 mRNA expression in LPS-induced vascular smooth muscle cells in vitro. Taken together, it is worth to investigate whether curcumin exerts anti-atherosclerotic efficacy in animal model in vivo.

\section{Acknowledgement}

We thank Dr. Diah Iskandriati and Silmi Mariyah, MSc for providing the isolation of rat smooth muscle explants at Laboratory of Microbiology and Immunology, Research Center for Primate, Bogor Agriculture University, Bogor, Indonesia.

\section{Funding Information}

This project was supported by Competency Grant from General Directorate of Higher Education, Ministry of Education and Culture, Republic of Indonesia (2012-2013).

\section{Author's Contributions}

Yanti: Manuscript writing and result verification Stephanie: Preparation for sample and cell culture

Yuliani: Preparation for sample treatment and molecular assays

F.G. Winarno: Data analysis, scientific discussion, and verification

Maggy T. Suhartono: Discussion, manuscript writing, and revision

\section{Ethics}

All authors have read and approved the manuscript.

\section{References}

Aggarwal, B.B., 2010. Targeting inflammationinduced obesity and metabolic diseases by curcumin and other nutraceuticals. Annu. Rev. Nutr., 30: 173-99.

DOI: 10.1146/annurev.nutr.012809.104755

Araujo, C.C. and L.L. Leon, 2001. Biological activities of curcuma longa L. Mem. Inst. Oswaldo Cruz., 96: 723-728. DOI: $10.1590 / \mathrm{S} 0074-02762001000500026$

Chang, L.Y., H.C. Wan, Y.L. Lai, Y.F. Kuo and T.Y. Liu et al., 2009. Areca nut extracts increased expression of inflammatory cytokines, tumor necrosis factor-alpha, interleukin-1beta, interleukin6 and interleukin-8, in peripheral blood mononuclear cells. J. Periodontal Res., 44: 175-183. DOI: $10.1111 /$ j.1600-0765.2008.01104.x

Cohen, A.N., M.S. Veena, E.S. Srivatsan and W.B. Wang, 2009. Suppression of interleukin 6 and 8 production in head and neck cancer cells with curcumin via inhibition of Ikappa beta kinase. Arch. Otolaryngol. Head Neck Surg., 135: 190-197.

DOI: 10.1001/archotol.135.2.190

Gunther, S., R.W. Alexander, W.J. Atkinson and M.A. Gimbrone, 1982. Functional angiotensin II receptors in cultured vascular smooth muscle cells. J. Cell Biol., 92: 289-298. DOI: 10.1083/jcb.92.2.289

Han, J., J.O. Lee, P.S. Tobias and R.J. Ulevitch, 1993. Endotoxin induces rapid protein tyrosine phosphorylation in 70Z/3 cells expressing CD14. J. Biol. Chem., 268: 25009-25014. PMID: 7693711

Li, Y., D.J. Samuvel, K.P. Sundararaj, M.F. LopesVirella and Y. Huang, 2010. IL-6 and high glucose synergistically upregulate MMP-1 expression by U937 mononuclear phagocytes via ERK1/2 and JNK pathways and c-Jun. J. Cell Biochem., 110: 248-259. PMID: 20225236

Lin, H.Y., S.C. Hou, S.C. Chen, M.C. Kao and C.C. $\mathrm{Yu}$ et al., 2012. (-)-Epigallocatechin gallate induces Fas/CD95-mediated apoptosis through inhibiting constitutive and IL-6-induced JAK/STAT3 signaling in head and neck squamous cell carcinoma cells. J. Agric. Food Chem., 60: 2480-2489. PMID: 22313388

Lin, Y.S., S.J. Tsai, M.W. Lin, C.T. Yang, M.F. Huang and M.H. $\mathrm{Wu}, 2011$. Interleukin-6 as an early chronic inflammatory marker in polycystic ovary syndrome with insulin receptor substrate-2 polymorphism. Am. J. Reprod. Immuno., 66: 527533. DOI: 10.1111/j.1600-0897.2011.01059.x

Lee, J.C., J.T. Laydon, P.C. McDonnell, T.F. Gallagher and S. Kumar et al., 1994. A protein kinase involved in the regulation of inflammatory cytokine biosynthesis. Nature, 372: 739-746.

DOI: $10.1038 / 372739 \mathrm{a} 0$ 
Rafiee, P., V.M. Nelson, S. Manley, M. Wellner and M. Floer et al., 2009. Effect of curcumin on acidic $\mathrm{pH}-$ induced expression of IL-6 and IL-8 in human esophageal epithelial cells (HET-1A): Role of PKC, MAPKs and NF-kappaB. Am. J. Physiol. Gastrointest. Liver Physiol., 296: G388-398.

DOI: 10.1152/ajpgi.90428.2008

Roughley, P.J. and D.A. Whiting, 1973. Experiments in the Biosynthesis of Curcumin. J. Chem. Soc., Perkin Trans., 1: 2379-2388. DOI: $10.1039 / \mathrm{P} 19730002379$

Schiborr, C., G.P. Eckert, J. Weissenberger, W.E. Müller and D. Schwamm et al., 2010. Cardiac oxidative stress and inflammation are similar in SAMP8 and SAMR1 mice and unaltered by curcumin and Ginkgo biloba extract intake. Curr. Pharm. Biotechnol., 11: 861-867. DOI: $10.2174 / 138920110793262006$

Stimpson, S.A., R.E. Esser, P.B. Carter, R.B. Sartor and W.J. Cromartie et al., 1987. Lipopolysaccharide induces recurrence of arthritis in rat joints previously injured by peptidoglycan-polysaccharide. J. Exp. Med., 165: 1688-1702. DOI: $10.1084 / \mathrm{jem} .165 .6 .1688$

Tuorkey, M. and K. Karolin, 2009. Anti-ulcer activity of curcumin on experimental gastric ulcer in rats and its effect on oxidative stress/antioxidant, IL-6 and enzyme activities. Biomed. Environ. Sci., 22: 488495. DOI: $10.1016 / \mathrm{S} 0895-3988(10) 60006-2$
Wang, S.L., Y. Li, Y. Wen, Y.F. Chen and L.X. Na et al., 2009. Curcumin, a potential inhibitor of upregulation of TNF-alpha and IL-6 induced by palmitate in 3T3-L1 adipocytes through NF-kappaB and JNK pathway. Biomed. Environ. Sci., 22: 3239. DOI: 10.1016/S0895-3988(09)60019-2

Weinstein, S. L., J.S. Sanghera, K. Lemke, A.L. DeFranco and S.L. Pelech, 1992. Bacterial lipopolysaccharide induces tyrosine phosphorylation and activation of mitogenactivated protein kinases in macrophages. J. Biol. Chem., 267: 14955-14962. PMID: 1321821

Wu, S.J., K.W. Tam, Y.H. Tsai, C.C. Chang and J.C. Chao, 2010. Curcumin and saikosaponin a inhibit chemical-induced liver inflammation and fibrosis in rats. Am. J. Chin. Med., 38: 99-111. DOI: $10.1142 / \mathrm{S} 0192415 \mathrm{X} 10007695$

Yanti, 2010. Anti-metalloproteinase-9 activities of selected Indonesian Zingiberaceae rhizome extracts in lipopolysaccharide-induced human vascular endothelial cells in vitro. Am. J. Biochem. Biotechnol., 7: 1-9. DOI: 10.3844/ajbbsp.2011.1.9

Zhang, Y., G. Pilon, A. Marette and V.E. Baracos, 2000. Cytokines and endotoxin induce cytokine receptors in skeletal muscle. Am. J. Physiol. Endocrinol. Metab., 279: 196-205. PMID: 10893340

Zhou, H., C.S. Beevers and S. Huang, 2011. The targets of curcumin. Curr. Drug Targets., 12: 332-347. 